\title{
Electrophilic Oxidation and [1,2]-Rearrangement of the Biindole Core of Birinapant
}

Yijun Deng, * Thomas Haimowitz, Matthew G. LaPorte, ${ }^{\dagger}$ Susan R. Rippin, Matthew D. Alexander, ${ }^{\ddagger}$ Pavan Tirunahari Kumar, Mukta S. Hendi, Yu-Hua Lee, and Stephen M. Condon*

TetraLogic Pharmaceuticals Corporation, 343 Phoenixville Pike, Malvern, Pennsylvania 19355, United States

Supporting Information

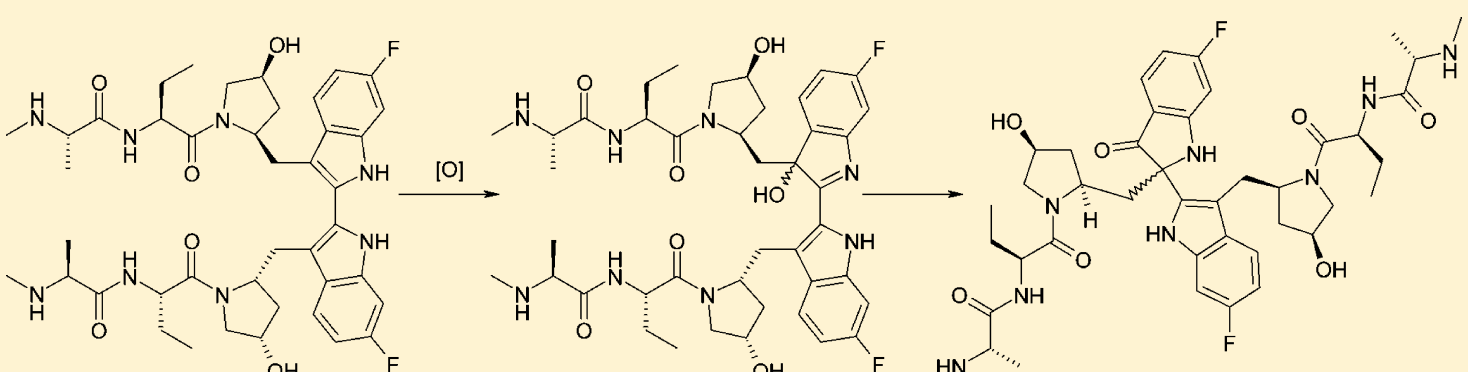

Birinapant (1)

2 and 3

5 and 6

ABSTRACT: Birinapant/TL32711 (1) is a bivalent antagonist of the inhibitor of apoptosis (IAP) family of proteins and was designed to mimic AVPI, the $N$-terminal tetrapeptide of the second mitochondria-derived activator of caspases (Smac/ DIABLO). Birinapant bound to the BIR3 domains of cIAP1, cIAP2, and XIAP with $K_{\mathrm{i}}$ values of 1,36 , and $45 \mathrm{nM}$, respectively. Birinapant-mediated activation of cIAP1 resulted in CIAP1 autoubiquitylation and degradation and correlated with inhibition of TNF-mediated NF- $\kappa \mathrm{B}$ activation, induction of tumor cell death in vitro, and tumor regression in vivo. Birinapant is being evaluated in Phase 1/2 trials for the treatment of cancer and hepatitis B virus (HBV) infection. After one year at accelerated storage conditions, a formulation of 1 afforded four degradants in $>0.1 \%$ abundance by HPLC analysis. The primary degradants (2 and 3) were formed via oxidation of the biindole core, while the secondary degradants (5 and 6) arose via [1,2]rearrangement of $\mathbf{3}$ and 2, respectively. Forced degradation conditions were developed, which allowed the isolation of $\mathbf{2}$ and 3 in multigram quantities. Novel deuterated analogues of 1 were prepared to determine the site of oxidation, and NMR experiments confirmed the chemical structures of 5 and $\mathbf{6}$. The de novo synthesis of 2, 3, 5, and $\mathbf{6}$ confirmed these experimental findings.

KEYWORDS: Birinapant, biindole, oxidation, degradation, rearrangement, stability, drug product

B irinapant/TL32711 (1) is a small-molecule antagonist of the inhibitor of apoptosis (IAP) family of proteins that is currently in clinical trials for the treatment of cancer and hepatitis B virus (HBV) infection. ${ }^{1-3}$ Structurally, 1 contains two $N(\mathrm{Me})$ Ala-Abu-Pro peptide chains attached to a central biindole core (Figure 1A). The discovery and development of birinapant drug substance has been reported. ${ }^{4,5}$ Birinapant drug product $(1 \mathrm{DP})$ is currently manufactured as a sterile-filtered, aqueous formulation, which is administered as an intravenous infusion. As part of an ongoing chemical development program, 1 DP has been evaluated for long-term stability at multiple conditions including $25^{\circ} \mathrm{C} / 60 \%$ relative humidity $(\mathrm{RH})$ and 40 ${ }^{\circ} \mathrm{C} / 75 \% \mathrm{RH}$. In the course of these investigations, partial degradation $(>0.1 \%)$ of 1 was observed on prolonged storage of $1 \mathrm{DP}$ at the accelerated storage condition of $40^{\circ} \mathrm{C} / 75 \% \mathrm{RH}$ (Figure 1B). High performance liquid chromatography (HPLC) and mass spectral (MS) analysis of these samples demonstrated that four degradants (i.e., 2, 3, 5, and 6) were formed by the addition of a single oxygen molecule to 1 (i.e., $M$ +16 ); degradants arising from the addition of two oxygen molecules (i.e., 4) were observed in lower quantities. ${ }^{6}$ In order to gain insight into the degradation process, we prepared each oxidative degradant via forced degradation and then confirmed their structures based on independent synthesis.

To generate sufficient quantities of the oxidative degradants, air was bubbled through an aqueous solution of 1 containing $0.1 \%$ acetic acid (HOAc) for 7 days thus affording a mixture of 2-6 albeit in differing ratios from the degradation of authentic 1 DP (Supplemental Figure S1). Using this process, we were able to generate gram-quantities of $\mathbf{2}$ and 3, which allowed for their chemical characterization by ${ }^{1} \mathrm{H}$ and ${ }^{13} \mathrm{C}$ NMR spectroscopy and mass spectrometry (MS).

Several possible mechanisms for the oxidation of $\mathbf{1}$ including amine oxidation, ${ }^{7}$ benzylic oxidation, ${ }^{8}$ and indole oxidation ${ }^{9}$ are supported by literature precedent. We observed that mixtures of $\mathbf{2}$ and $\mathbf{3}$ reverted to $\mathbf{1}$ under standard palladium-catalyzed hydrogenation conditions thus supporting these proposed

Received: December 1, 2015

Accepted: January 9, 2016

Published: January 9, 2016 
A

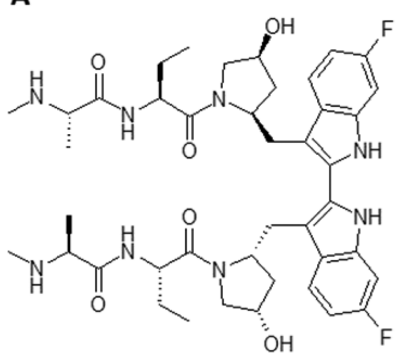

B

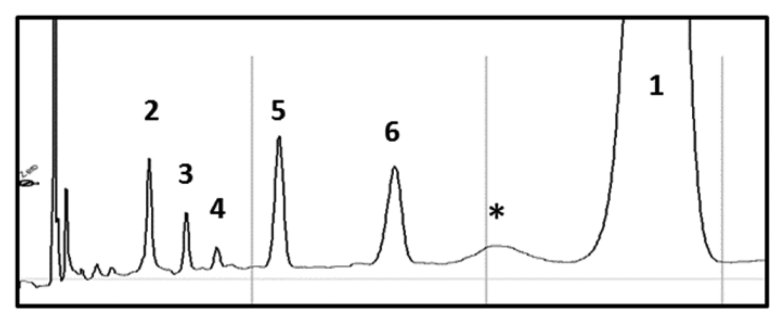

Figure 1. (A) Chemical structure of birinapant/TL32711 (1). (B) HPLC profile of $1 \mathrm{DP}$ after extended storage at $40{ }^{\circ} \mathrm{C} / 75 \% \mathrm{RH}$ indicating the formation of oxidative degradants 2 through 6 . Asterisk $(*)$ indicates a process impurity, which is unrelated to the degradation process.

modes of oxidation (data not shown). The product of $\mathrm{N}$ terminal amine oxidation was prepared by independent synthesis and shown not to correlate with any of the observed degradants by HPLC analysis (Supplemental Scheme S1).

Benzylic oxidation adjacent to an indole moiety is reported to occur under free-radical conditions when DDQ is employed as the oxidant. ${ }^{8}$ In contrast, electrophilic oxidation using dimethyldioxirane (DMDO) is reported to result in the direct oxidation of the indole ring to afford $3 H$-indol-3-ols. ${ }^{9}$ To distinguish between these two oxidative pathways, we incorporated deuterium atoms at the benzylic positions of 1 (Scheme 1). ${ }^{10}$ Reduction of 7 with $\mathrm{NaBH}_{4}-d_{4}$ furnished 8,

Scheme 1. Synthesis of Deuterated Birinapant, 1- $d_{4}$

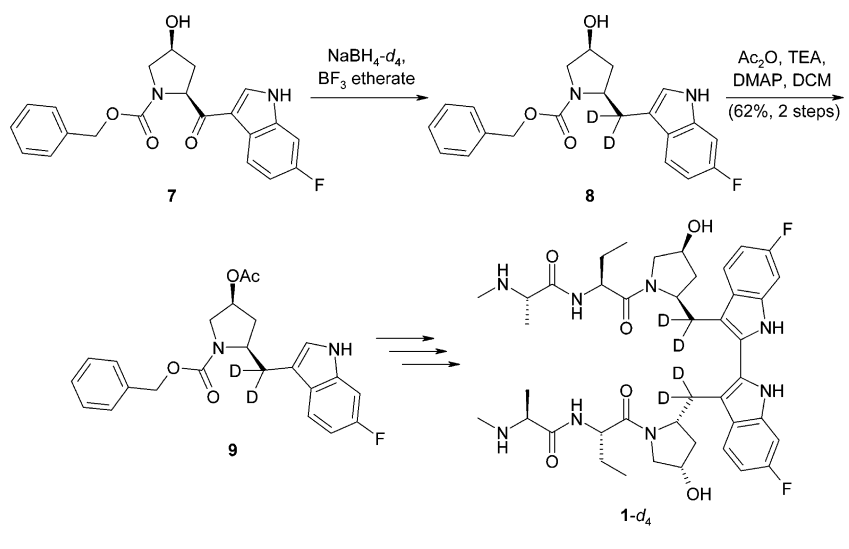

which contained two benzylic deuterium atoms. Following protection of the hydroxy group, deuterated 9 was subjected to TFA-mediated indole dimerization; ${ }^{10-12}$ further elaboration using known methods afforded $1-d_{4} \cdot{ }^{4}$

Under forced oxidation conditions (i.e., $0.1 \%$ aqueous HOAc, 7 days), 1- $d_{4}$ afforded the same mixture of oxidative degradants by HPLC analysis (Supplemental Figure S2); the observed molecular ion for each degradant confirmed the retention of all four deuterium atoms. Thus, benzylic oxidation, which would have resulted in the loss of one deuterium atom, was eliminated as an operative oxidative pathway.

To confirm direct oxidation of the biindole core, we subjected 1 to electrophilic oxidation using DMDO. ${ }^{9}$ Unfortunately, this reaction was unsuccessful likely due to the presence of the two basic nitrogen atoms of 1 . Thus, we performed the oxidation on fully protected intermediate $\mathbf{1 0}$ (Scheme 2). Treatment of $\mathbf{1 0}$ with DMDO, generated in situ by the combination of oxone and acetone, provided a mixture of two diastereomeric hydroxyindolenines (11), each bearing four deuterium atoms further confirming the biindole moiety as the site of oxidation of $\mathbf{1}$. Removal of the Boc and acetyl protective groups afforded 2- $d_{4}$ and $3-d_{4}$, which coeluted with authentic 2 and 3 from the 1 DP stability study. The absolute stereochemistry at the C3-indole position of $2-d_{4}$ and $3-d_{4}$ remains unknown and thus has been assigned arbitrarily.

These results were confirmed by independent synthesis of $\mathbf{2}$ and 3 from the Boc-Abu-coupled intermediate (12, Scheme 3). As expected, oxidation of $\mathbf{1 2}$, a previously reported intermediate in the synthesis of $\mathbf{1},{ }^{4,5}$ afforded the hydroxyindolenines $\mathbf{1 3}$ and 14 as a separable mixture of stereoisomers. Independent elaboration of 13 or 14 afforded synthetic 2 or 3, respectively, which coeluted with authentic 2 and 3 derived from the degradation of 1 DP (Supplemental Figure S3) and were identical by ${ }^{1} \mathrm{H}$ and ${ }^{13} \mathrm{C}$ NMR and MS analysis to 2 and 3 formed via forced degradation of 1 . Taken together, these results demonstrated that oxidative degradants $\mathbf{2}$ and $\mathbf{3}$ were formed via the biindole oxidation of $\mathbf{1}$.

Movassaghi et al. reported that 2-aryl-substituted hydroxyindolenines like 2 and 3 rearranged to either $1 H$ - $\left[2,2^{\prime}\right]$ biindolyl-3-ones or $1^{\prime}, 3^{\prime}$-dihydro- $1 \mathrm{H}$-[2,3'] biindolyl-2' -ones depending upon the reaction conditions and that these two regioisomeric rearrangement products could be distinguished by examining the chemical shift of the nascent carbonyl resonance in the ${ }^{13} \mathrm{C}$ NMR spectra. ${ }^{9}$ More recently, Qi et al. ${ }^{13}$ and $\mathrm{Han}$ and Movassaghi ${ }^{14}$ demonstrated that biindole-derived hydroxyindolenines rearranged under thermal or acidic conditions to afford $1 H$-[2,2' $]$-biindolyl-3-ones (infra).

To address whether 2 or 3 would undergo this rearrangement, we warmed an aqueous solution of 2 containing $0.1 \%$ HOAc for $24 \mathrm{~h}$ at $95{ }^{\circ} \mathrm{C}$. Under this condition, 2 readily rearranged to 6 (Supplemental Figure S5). In a separate experiment, we observed that 3 rearranged to 5 under identical reaction conditions. Taken together, these data demonstrated that oxidation of $\mathbf{1}$ occurred at the biindole core to afford hydroxyindolenines 2 and 3, which further rearranged to 6 and 5, respectively. However, whether $\mathbf{2}$ or $\mathbf{3}$ rearranged to provide $1 H$ - $\left[2,2^{\prime}\right]$-biindolyl-3-ones or the isomeric $1^{\prime}, 3^{\prime}$-dihydro- $1 H$ $\left[2,3^{\prime}\right]$ biindolyl-2'-ones remained unresolved (Supplemental Figure S4).

Owing to the structural complexity of 5 and $\mathbf{6}$, we performed the oxidation/rearrangement on a simpler biindole substrate in order to independently confirm the chemical structures of $\mathbf{5}$ and 6. Biindole $\mathbf{1 5}$ is employed in the synthesis of $\mathbf{1}^{4,5}$ Treatment of 15 under modified DMDO-mediated oxidation conditions provided a mixture of hydroxyindolenines $\mathbf{1 6}$ and $\mathbf{1 7}$ (Scheme 4). As with 2 and 3 (supra), the absolute chemistry at the C3-indole positions of $\mathbf{1 6}$ and $\mathbf{1 7}$ is unknown and therefore has been assigned arbitrarily. This mixture was then subjected 
Scheme 2. Preparation of Synthetic Oxidative Degradants 2- $d_{4}$ and 3- $d_{4}$ from 10
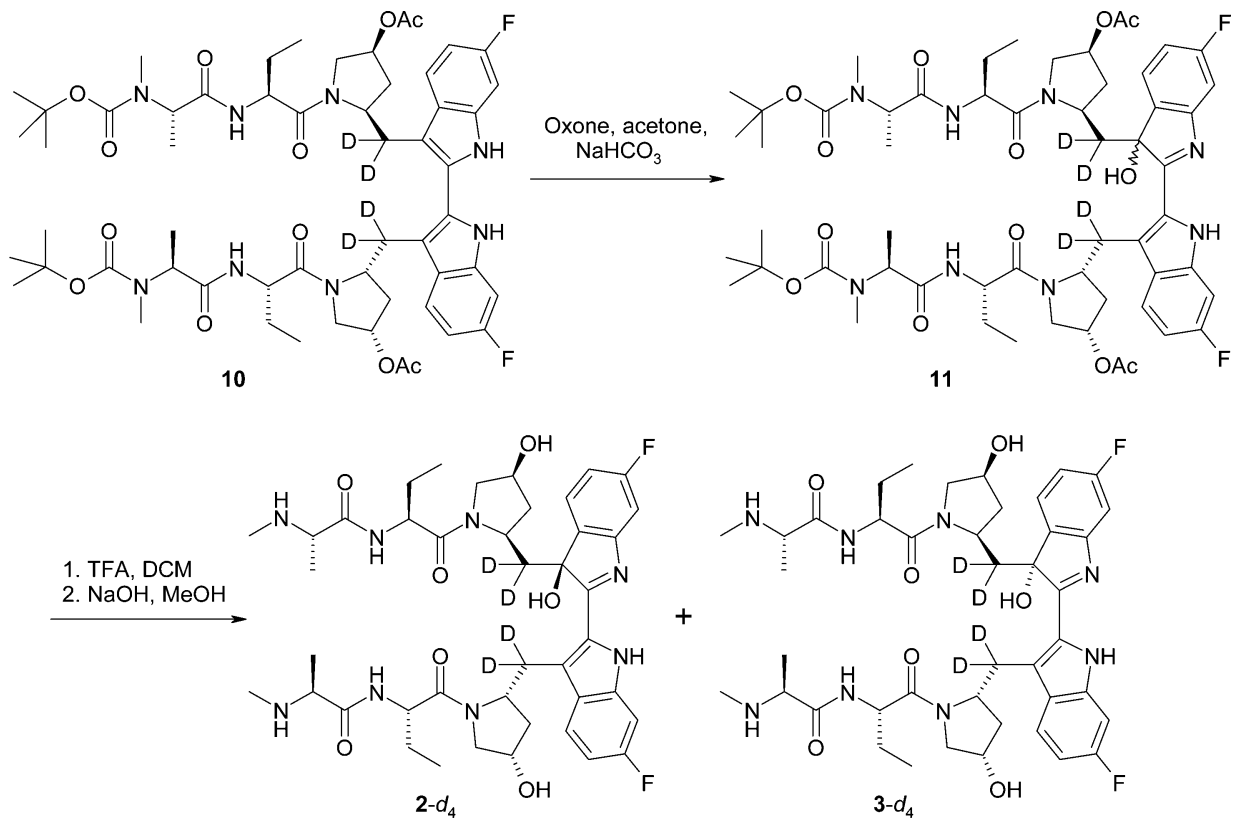

Scheme 3. Preparation of Oxidative Degradants 2 and 3 from 12

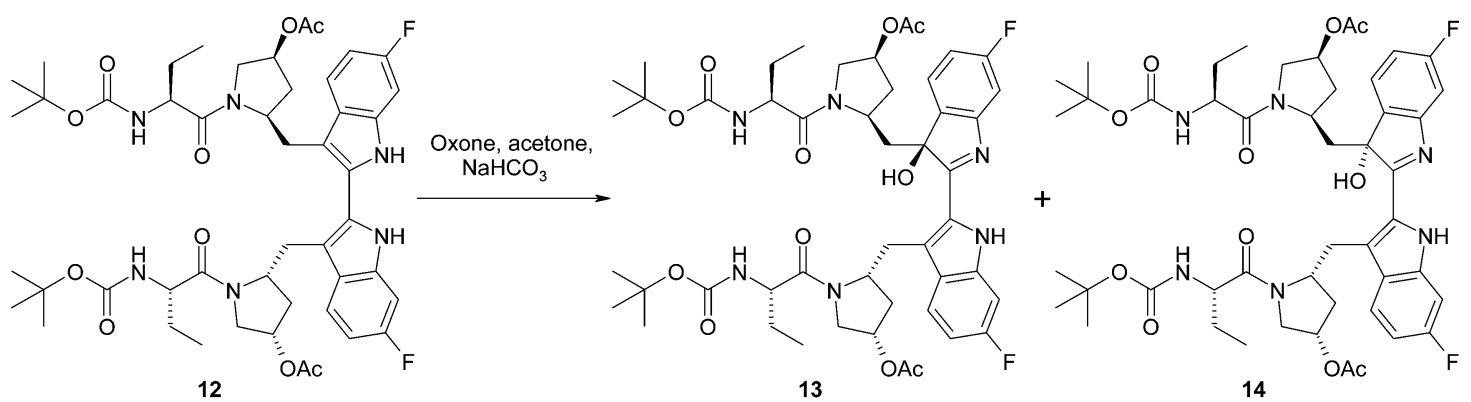

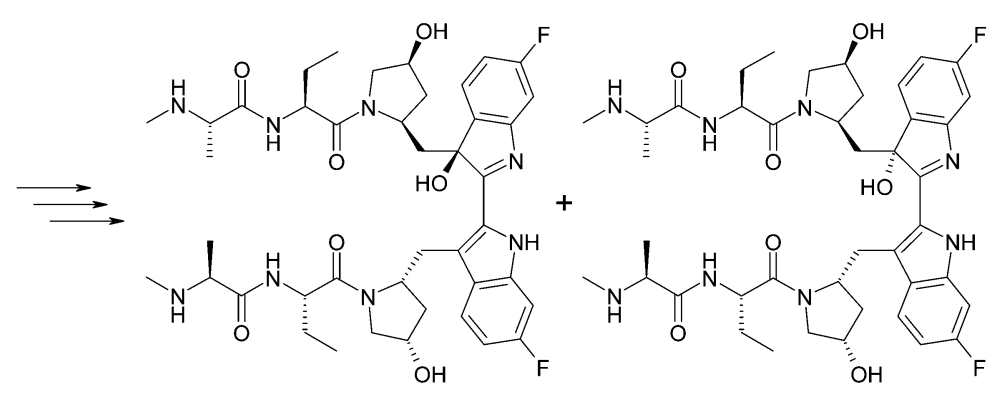

2

3

to modified rearrangement conditions $(0.1 \%$ HOAc in toluene at $100{ }^{\circ} \mathrm{C}$ ) to afford a separable mixture of 18 and 19. The observed ${ }^{13} \mathrm{C}$ chemical shifts for the nascent carbonyl groups of 18 and 19 were $\delta 200.4$ and $\delta$ 199.6, respectively, thus suggesting that hydroxyindolenines 16 and 17 rearranged to $1 \mathrm{H}$-[2,2']-biindolyl-3-ones 18 and 19 and not to the structurally related $1^{\prime}, 3^{\prime}$-dihydro- $1 H$ - $\left[2,3^{\prime}\right]$ biindolyl-2' -ones (not shown). In a separate series of experiments, we demonstrated that, in fact, exposure of $\mathbf{1 6}$ to the rearrangement conditions exclusively afforded 18, while independent treatment of 17 provided 19 thereby demonstrating the stereospecific nature of the $[1,2]$-rearrangement process (data not shown). Importantly, the absolute stereochemistry at the quaternary centers of $\mathbf{1 8}$ and $\mathbf{1 9}$ is unresolved and has thus been assigned arbitrarily based on the assigned configurations of 16 and 17 , respectively.

Final elucidation of the degradation pathway came from the conversion of 18 into 6 using our standard HATU-mediated peptide coupling strategy (Scheme 5). ${ }^{4}$ Hydrogenolytic removal of the two $\mathrm{Cbz}$ protective groups of $\mathbf{1 8}$ afforded the bis-pyrrolidine (20), which was then coupled to Cbz-Abu-OH. Further elaboration of the peptide chains provided 6 which was identical by HPLC, MS, ${ }^{1} \mathrm{H}$, and ${ }^{13} \mathrm{C}$ NMR analyses to authentic 6 formed either via the degradation of 1 DP (Supplemental Figure S5) or via acid-mediated rearrangement of 2 (Supplemental Figure S4).

In an analogous fashion, $1 H$-[2,2']-biindolyl-3-one 19 was converted in several steps to 5 , which was identical to the 
Scheme 4. Synthesis and [1,2]-Rearrangement of Hydroxyindolenines 16 and 17
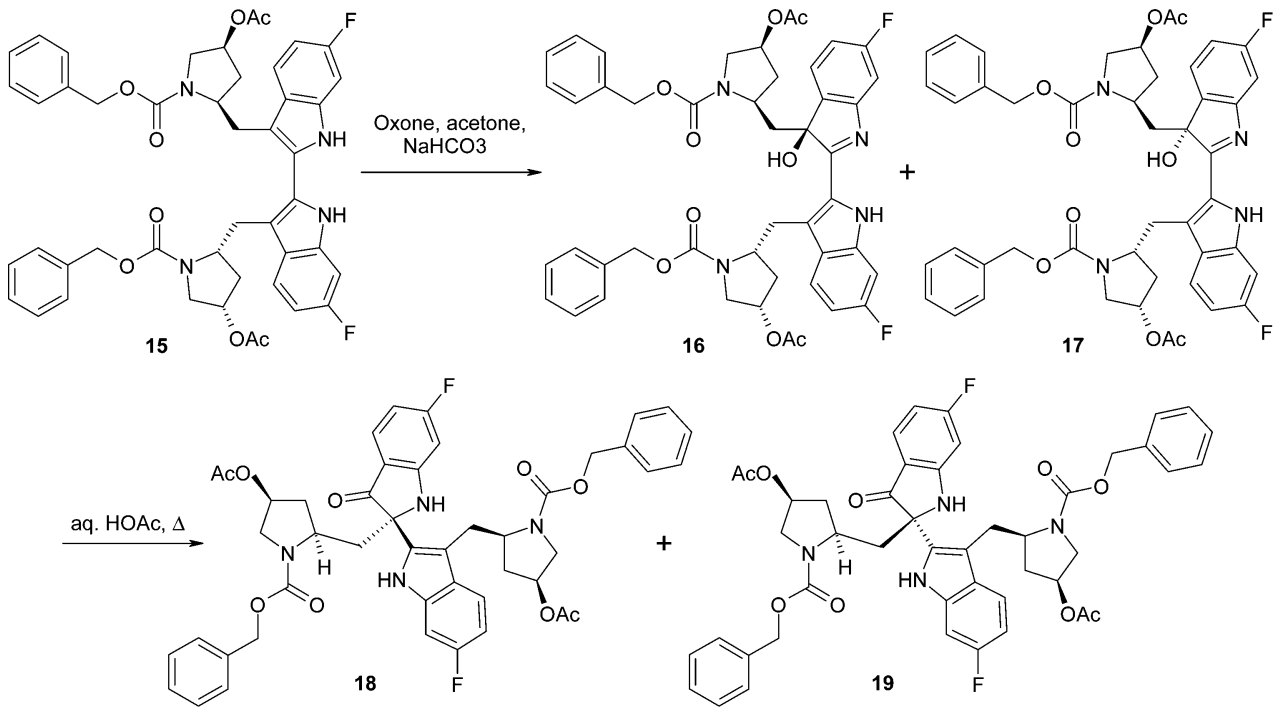

Scheme 5. Transformation of $1 H$-[2,2']-Biindolyl-3-one 18 into Oxidative Degradant 6
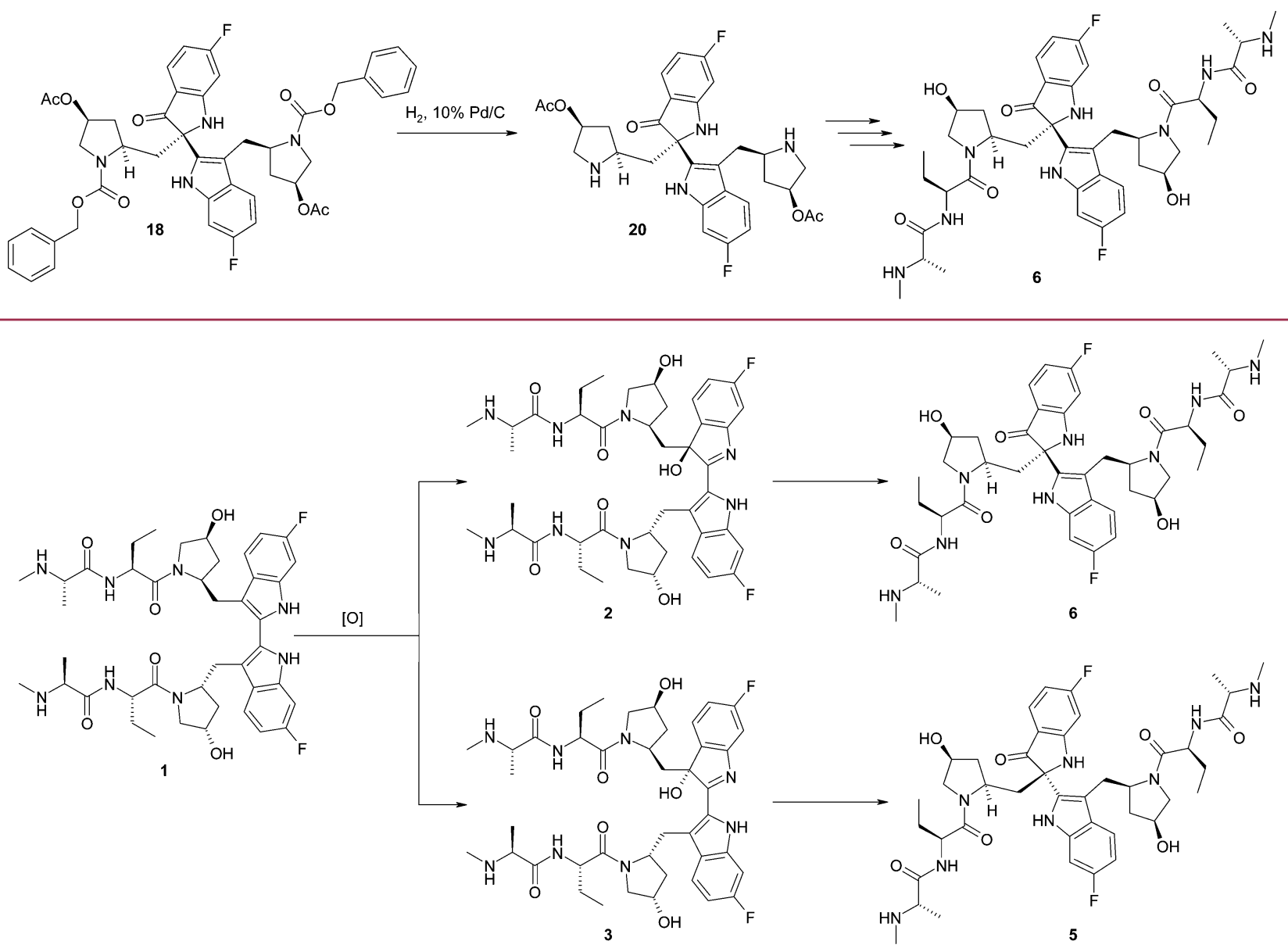

Figure 2. Proposed pathway for the oxidative degradation of $\mathbf{1}$.

authentic standard (data not shown). Interestingly, during the Cbz group removal from 19, an azepine-containing product was isolated in modest yield together with the desired bispyrrolidine (Supplemental Scheme S2). No effort was made to optimize this reaction; however, the azepine was likely formed via the intramolecular reductive amination of the intermediate bis-pyrrolidine. A similar intramolecular cyclization was recently described in the synthesis of trigonoliimine C. ${ }^{13-15}$

Birinapant drug product (1 DP) is a sterile, aqueous solution, which is administered in the clinic by intravenous infusion. During the investigation of long-term storage conditions for 1 
DP, we observed the formation of four oxidative degradants at $>0.1 \%$ occurrence by HPLC analysis. To clarify the degradation process and support further drug product development, we isolated 2, 3, 5, and 6 following forced degradation of 1 and determined their chemical structures via independent synthesis.

This investigation demonstrated that the central biindole core of 1 reacted with atmospheric oxygen (or a transition metal oxo species) to afford two primary oxidative degradants 2 and 3, which were diastereomeric at the indole C3 position. ${ }^{14}$ Forced degradation of $1-d_{4}$ confirmed that oxidation did not occur at the benzylic positions of $\mathbf{1}$. Both hydroxyindolenines 2 and 3 could be prepared in gram-quantities by forced degradation of $\mathbf{1}$ and these synthetic products were identical by HPLC and mass spectral analysis to those formed on extended storage of $1 \mathrm{DP}$ at $\geq 40{ }^{\circ} \mathrm{C}$.

The observation that an acidic solution of hydroxyindolenine 2 transformed with heating to $1 H$-[2,2']-biindolyl-3-one 6 further corroborated these results. Notably, diastereomer 3 was shown to convert to $\mathbf{5}$ under identical conditions. Contemporaneous with this investigation, $\mathrm{Qi}$ et al. $^{13}$ and $\mathrm{Han}$ and Movassaghi ${ }^{14}$ demonstrated a similar Wagner-Meerwein-type $[1,2]$-rearrangement of hydroxyindolenines derived from $2,2^{\prime}$ bis-tryptamines en route to the total syntheses of the trigonoliimines. Thus, the oxidative pathway for the degradation of $1 \mathrm{DP}$ at elevated temperature is summarized in Figure 2.

The ultimate goal of our drug development program was to develop a formulation of $\mathbf{1}$, which achieved ambient temperature stability on extended storage. To further aid in this process, a thorough understanding of the oxidizing species, i.e., molecular oxygen, peroxides, etc., effect of the container closure system, i.e., composition of glass vial, and the application of pharmaceutically acceptable antioxidants, i.e., BHT, tocopherol, etc., may be required. The insights gained from this study will aid in the development of stabilized formulations of $\mathbf{1}$.

\section{EXPERIMENTAL PROCEDURES}

Chemistry. Birinapant (1), 12, and 15 were prepared following reported procedures. ${ }^{4,5}$ Deuterated intermediates $\mathbf{8}, \mathbf{9}, \mathbf{1 0}$, and $\mathbf{1}-d_{4}$ were prepared using standard modifications of those methods. ${ }^{10}{ }^{1} \mathrm{H}$ and ${ }^{13} \mathrm{C}$ NMR and mass spectral characterization of $2,3,5,6,16,17$, 18, and 19 are provided in the Supporting Information.

Representative procedures for the forced degradation of $\mathbf{1}$, the DMDO-mediated oxidation of $\left[2,2^{\prime}\right]$-biindoles, and rearrangement to the resultant $1 H-\left[2,2^{\prime}\right]$-biindolyl-3-ones are provided below.

Isolation of 2 and 3 Following the Forced Degradation of Birinapant (1). Birinapant $(1,5.0 \mathrm{~g}, 6.2 \mathrm{mmol})$ was dissolved in water containing $0.1 \% \mathrm{HOAc}(250 \mathrm{~mL})$. Air was gently bubbled through the colorless solution at ambient temperature. After 7 days, HPLC analysis revealed $85 \%$ conversion of 1 to afford 2 ( 41 area \%), 3 (25 area \%), 4 (mixture of isomers, 6 area \%), 5 (5 area \%), and $\mathbf{6}$ (2 area \%). The yellow-colored solution was concentrated, and the residue was purified by RP-HPLC to provide $1.4 \mathrm{~g}$ of $2(27 \%)$ and $0.7 \mathrm{~g}$ of 3 (14\%) as yellow-colored solids.

Preparation of 6 via the [1,2]-Rearrangement of 2. Primary degradant $2(140 \mathrm{mg}, 0.17 \mathrm{mmol})$ was dissolved in water containing $0.1 \%$ HOAc $(10 \mathrm{~mL})$. The resulting yellow-colored solution was warmed to $95{ }^{\circ} \mathrm{C}$ for $24 \mathrm{~h}$ at which time HPLC analysis revealed $>95 \%$ conversion of 2 to 6 . The reaction mixture was concentrated, and the residue was purified by RP-HPLC to afford $110 \mathrm{mg}$ of 6 (79\%) as a yellow-colored solid.

Preparation of 16 and 17 via DMDO-Mediated Oxidation of 15. To suppress overoxidation of the biindole moiety, a biphasic modification of the DMDO-mediated oxidation was applied. ${ }^{9}$ To a heterogeneous mixture of saturated aqueous $\mathrm{NaHCO}_{3}(30 \mathrm{~mL})$ and acetone $(30 \mathrm{~mL})$ was slowly added oxone $(3.6 \mathrm{~g}, 5.8 \mathrm{mmol})$ in deionized water $(50 \mathrm{~mL})$ at $0{ }^{\circ} \mathrm{C}$. The resulting homogeneous mixture was stirred at $0{ }^{\circ} \mathrm{C}$ for $1 \mathrm{~h}$ followed by the slow addition of $15(4.3 \mathrm{~g}$ $5.3 \mathrm{mmol})$ in DCM $(100 \mathrm{~mL})$. After $1 \mathrm{~h}$ at $0{ }^{\circ} \mathrm{C}$, the reaction mixture was diluted with deionized water $(100 \mathrm{~mL})$ and DCM $(100 \mathrm{~mL})$. The organic layer was separated, and the aqueous phase was extracted with DCM $(2 \times 50 \mathrm{~mL})$. The combined organic extracts were washed with brine and dried over anhydrous $\mathrm{Na}_{2} \mathrm{SO}_{4}$, filtered, and concentrated. The crude residue was purified by RP-HPLC to provide $1.1 \mathrm{~g}(26 \%)$ of 16 (early eluting product) and $2.7 \mathrm{~g}(63 \%)$ of 17 (late eluting product) as yellow-colored solids.

Preparation of 18 via [1,2]-Rearrangement of 16. A solution containing $16(1.1 \mathrm{~g}, 1.31 \mathrm{mmol})$ in toluene $(40 \mathrm{~mL})$ and HOAc $(0.5$ $\mathrm{mL}$ ) was stirred at $100{ }^{\circ} \mathrm{C}$. After $4 \mathrm{~h}, \mathrm{HPLC}$ analysis revealed complete conversion to 18. The solvent was removed in vacuo, and the crude residue was purified by RP-HPLC to yield $950 \mathrm{mg}$ of $\mathbf{1 8}(86 \%)$ as a yellow-colored solid.

\section{ASSOCIATED CONTENT}

\section{(5) Supporting Information}

The Supporting Information is available free of charge on the ACS Publications website at DOI: 10.1021/acsmedchemlett.5b00461.

NMR $\left({ }^{1} \mathrm{H},{ }^{13} \mathrm{C}\right)$ and mass spectral characterization of 1$d_{4}, 2,3,5,6,16,17,18$, and 19 (PDF)

\section{AUTHOR INFORMATION}

\section{Corresponding Authors}

*Phone: 001-610-889-9900. Fax: 001-610-889-9994. E-mail: yijun.deng@tetralogicpharma.com.

*E-mail: stephen.condon@tetralogicpharma.com.

\section{Present Addresses}

${ }^{\dagger}$ Department of Chemistry, Chemical Methodologies and Library Development, University of Pittsburgh, Pittsburgh, Pennsylvania 15260, United States.

$¥$ Celgene Corp., 10300 Campus Point Drive, Suite 100, San Diego, California 92121, United States.

\section{Author Contributions}

Y.D., T.H., M.G.L., S.R.R., M.D.A., P.T.K., M.S.H., Y.-H.L., and S.M.C. contributed to the design and synthesis of compounds.

Notes

The authors declare no competing financial interest.

\section{ACKNOWLEDGMENTS}

The authors wish to acknowledge the support from our colleagues at TetraLogic Pharmaceuticals (Malvern, PA).

\section{ABBREVIATIONS USED}

Abu, $\alpha$-aminobutyric acid; AVPI, alanine-valine-proline-isoleucine tetrapeptide; BHT, butylated hydroxytoluene; BIR3, baculovirus IAP repeat domain 3; Cbz, benzyloxycarbonyl; cIAP, cellular IAP1 or cIAP2; DDQ, 2,3-dichloro-5,6-dicyano1,4-benzoquinone; DIABLO, direct IAP binding protein with low pI (also, Smac); DMDO, dimethyldioxirane; DMSO, dimethyl sulfoxide; DP, drug product; HPLC, high-performance liquid chromatography; HOAc, acetic acid; IAP, inhibitor of apoptosis proteins; LC/MS, liquid chromatography coupled to mass spectrometry; ML-IAP, melanoma IAP; MS, mass spectrum or spectrometry; $\mathrm{NaBH}_{4}$, sodium borohydride; NMR, nuclear magnetic resonance; [O], oxidation; oxone, potassium peroxymonosulfate; $\mathrm{RH}$, relative humidity; Smac, second mitochondria-derived activator of caspases (also, DIABLO); TFA, trifluoroacetic acid; TNF, tumor necrosis factor; TNFR1, TNF receptor 1; XIAP, X chromosome-linked IAP 


\section{REFERENCES}

(1) Benetatos, C. A.; Mitsuuchi, Y.; Burns, J. M.; Neiman, E. M.; Condon, S. M.; Yu, G.; Seipel, M. E.; Kapoor, G. S.; LaPorte, M. G.; Rippin, S. R.; Deng, Y.; Hendi, M. S.; Kumar, P. T.; Lee, Y.-H.; Haimowitz, T.; Alexander, M. D.; Graham, M. A.; Weng, D.; Shi, Y.; McKinlay, M. A.; Chunduru, S. K. Birinapant (TL32711), a bivalent SMAC mimetic, targets TRAF2-associated cIAPs, abrogates TNFinduced NF- $\kappa \mathrm{B}$ activation, and is active in patient-derived xenograft models. Mol. Cancer Ther. 2014, 13, 867-879.

(2) Ebert, G.; Preston, S.; Allison, C.; Cooney, J.; Toe, J. G.; Stutz, M. D.; Ojaimi, S.; Scott, H. W.; Baschuk, N.; Nachbur, U.; Torresi, J.; Chin, R.; Colledge, D.; Li, X.; Warner, N.; Revill, P.; Bowden, S.; Silke, J.; Begley, C. G.; Pellegrini, M. Eliminating hepatitis B by antagonizing cellular inhibitors of apoptosis. Proc. Natl. Acad. Sci. U. S. A. 2015, 112, 5803-5808.

(3) Ebert, G.; Allison, C.; Preston, S.; Cooney, J.; Toe, J. G.; Stutz, M. D.; Ojaimi, S.; Baschuk, N.; Nachbur, U.; Torresi, J.; Silke, J.; Begley, C. G.; Pellegrini, M. Eliminating hepatitis B by antagonizing cellular inhibitors of apoptosis. Proc. Natl. Acad. Sci. U. S. A. 2015, 112, 5803-5808.

(4) Condon, S. M.; Mitsuuchi, Y.; Deng, Y.; LaPorte, M. G.; Rippin, S. R.; Haimowitz, T.; Alexander, M. D.; Kumar, P. T.; Hendi, M. S.; Lee, Y.-H.; Benetatos, C. A.; Yu, G.; Kapoor, G. S.; Neiman, E.; Seipel, M. E.; Burns, J. M.; Graham, M. A.; McKinlay, M. A.; Li, X.; Wang, J.; Shi, Y.; Feltham, R.; Bettjeman, B.; Cumming, M. H.; Vince, J. E.; Khan, N.; Silke, J.; Day, C. L.; Chunduru, S. K. Birinapant - A Smacmimetic with Improved Tolerability for the Treatment of Solid Tumors and Hematological Malignancies. J. Med. Chem. 2014, 57, 3666-3677.

(5) Deng, Y.; Xie, Q.; LaPorte, M. G.; Chasnoff, A. T. A.; Mortenson, M. A.; Patra, D.; Putrelo, S. A.; Antonovich, R. S.; Cao, H.; Yan, J.; Cooper, A. J.; Rippin, S. R.; Alexander, M. D.; Kumar, P. T.; Hendi, M. S.; Lee, Y.-H.; Haimowitz, T.; Condon, S. M. Process Development and Synthesis of Birinapant - Large Scale Preparation and Acidmediated Dimerization of the Key Indole Intermediate. Org. Process Res. Dev. 2016, DOI: 10.1021/acs.oprd.5b00390.

(6) The composition and chemical structure(s) of 4 remains undetermined. We suggest that degradants $\mathbf{4}$ are formed via the subsequent oxidation and/or rearrangement of the nonoxidized indole moiety of $2,3,5$, or 6 .

(7) Kung, K. K.-Y.; Wong, K. F.; Leung, K.-C.; Wong, M.-K. Nterminal $\alpha$-amino group modification of peptides by an oxime formation-exchange reaction sequence. Chem. Commun. 2013, 49, 6888-6890.

(8) Nicolaou, K. C.; Snyder, S. A.; Huang, X.; Simonsen, K. B.; Koumbis, A. E.; Bigot, A. Studies toward Diazonamide A: Initial Synthetic Forays Directed toward the Originally Proposed Structure. J. Am. Chem. Soc. 2004, 126, 10162-10173.

(9) Movassaghi, M.; Schmidt, M. A.; Ashenhurst, J.A. Stereoselective Oxidative Rearrangement of 2-Aryl Tryptamine Derivatives. Org. Lett. 2008, 10, 4009-4012.

(10) Condon, S. M.; Deng, Y.; LaPorte, M. G.; Rippin, S. R. 2-(1HIndoyl-3-ylmethyl)-pyrrolidine dimer as Smac mimetic. US 8,283,372, 2012.

(11) Bergman, J.; Koch, E.; Pelcman, B. Reactions of Indole-3-acetic Acid Derivatives in Trifluoroacetic Acid. Tetrahedron Lett. 1995, 36, 3945-3948.

(12) Gilbert, E. J.; Van Vranken, D. L. Control of Dissymmetry in the Synthesis of (+)-Tjipanazole F2. J. Am. Chem. Soc. 1996, 118, 55005501.

(13) Qi, X.; Bao, H.; Tambar, U. K. Total Synthesis of ( \pm )-Trigonoliimine $C$ via Oxidative Rearrangement of an Unusual Bis-Tryptamine. J. Am. Chem. Soc. 2011, 133, 10050-10053.

(14) Han, S.; Movassaghi, M. Concise Total Synthesis and Stereochemical Revision of All (-)-Trigonoliimines. J. Am. Chem. Soc. 2011, 133, 10768-10771.

(15) Han, S.; Morrision, K. C.; Hergenrother, P. J.; Movassaghi, M. Total Synthesis, Stereochemical Assignment, and Biological Activity of All Known (-)-Trigonoliimines. J. Org. Chem. 2014, 79, 473-486. 